\title{
AGE DIFFERENCES IN PERCEPTIONS OF CONTROL IN SOCIAL RELATIONSHIPS*
}

\author{
ELIZABETH L. HAY \\ University of Florida, Gainesville \\ KAREN L. FINGERMAN \\ Purdue University
}

\begin{abstract}
To date, few studies have examined perceptions of control in interpersonal relationships, and whether such perceptions reflect individual characteristics (e.g., age) and features of relationships (e.g., quality). One hundred and eighty-seven individuals aged 13 to $99(M=45.62, S D=25.69)$ provided information about their close and problematic relationships and their perceptions of control over those relationships. Multilevel modeling revealed that both relationship features and individual characteristics were associated with perceptions of control in relationships. Specifically, individuals felt more control in their marital relationships, and in relationships characterized by higher quality and fewer worries. Age differences in individuals' perceptions of control in relationships appear to reflect age-related shifts in perceptions of control in the parent-child tie.
\end{abstract}

\section{INTRODUCTION}

Theorists argue that, as individuals grow older, they increasingly experience negative life events (e.g., illness, loss of social roles) that may diminish their sense of control (Mirowsky, 1995; Rodin, 1986; Thompson \& Spacapan, 1991). Yet,

*This study was funded by grant \# AG1448401, “Adults' Reasoning about Social Problems across Adulthood" from the National Institutes on Aging awarded to the second author. This article was written while the first author was supported by graduate fellowships from the Pennsylvania State University and the National Science Foundation.

(c) 2005, Baywood Publishing Co., Inc. 
empirical findings have not consistently found a decrease in perceptions of control with age. Indeed, researchers have found individuals' perceptions of control are not constant across the different areas of their lives (Brandstädter \& Rothermund, 1994; Lachman, 1986; Lachman \& Weaver, 1998; Nurmi, Pulliainen, \& Salmelo-Aro, 1992). Furthermore, age differences in perceptions of control are not necessarily uniform across different areas of life. For example, Lachman and Weaver found that older adults felt more control over their work, finances, and marriages than younger adults, but also felt less control over their children and sex lives than younger adults. Consequently, adults may experience less control over some areas of their lives as they grow older, yet experience more control in others. This study examined control over personal relationships-individuals' perceptions that they could manage the quality of their relationships.

It is important to consider perceptions of control over relationships for a number of reasons. Relationships appear to contribute to health and well-being across adulthood (e.g., Antonucci, 2001; Berkman, Glass, Brissette, \& Seeman, 2000), and some research suggests perceptions of control over relationships may be one pathway through which relationships enhance health (Bisconti \& Bergeman, 1999; Krause, 1995). Similarly, perceptions of control over life "in general" have been linked to health and well-being (for a review, see Rodin \& Timko, 1992), and scholars have suggested that perceptions of control in relationships contribute to general perceptions of control (e.g., Bandura, 1997; Krause, 1995; Levenson, 1973a; Skinner, 1992). Given the potential importance of perceptions of control in relationships to perceptions of control in general, and to health and well-being in particular, this study examined four questions: 1) What characteristics of relationships are associated with perceptions of control in those relationships?

2) Do perceptions of control vary across different types of relationships?

3) Are there age differences in perceptions of control in the social domain? and

4) Are perceptions of control in relationships associated with general perceptions of control?

\section{Characteristics of Relationships and Perceptions of Control in Relationships}

Implicit in existing research and theory is the idea that individuals' perceptions of control in relationships are not simply the result of a general orientation toward all relationships (e.g., Cook, 1993; Krause, 1995; Lachman \& Weaver, 1998). Rather, such perceptions reflect the features of each relationship. A number of studies employing different methodologies and focusing on various relationships indicate that individuals typically feel more control over high-quality relationships, and less control over problem-ridden relationships (Cook, 1993; Lachman \& Weaver, 1998; Martini, Grusec, \& Bernardini, 2001). Both Cook (1993) and Lachman and Weaver (1998) found that individuals felt more control within family ties characterized by high relationship quality. Similarly, 
Martini et al., (2001) found that mothers' and daughters' relationship satisfaction and perceptions of control were positively associated. Conversely, Cook (1993) found high negative reciprocity was associated with lower perceived control in nuclear family ties. Consistent with past research, we expected perceptions of relationship quality to be positively associated with perceptions of control.

None of these prior studies, however, explicitly considered perceptions of control within problematic relationships. As well these studies focus primarily on relationship quality and do not consider other aspects of relationships that may be relevant to perceptions of control therein. Consequently, it is difficult to determine from these studies the extent of variability in individuals' perceptions of control in relationships, or the variety of relationship qualities that are associated with perceptions of control. Thus, to add to existing knowledge, we examined problematic as well as close relationships.

To build on extant research, we also considered the role of an additional relationship characteristic: worry. A small line of research suggests that worrying about relationships may be linked with perceptions of control. Freeston and colleagues found that individuals worry when they believe they lack control (Freeston, Rheaume, Letarte, Dugas, \& Ladouceur, 1994). Further, worrying both about relationships ending and the disapproval of social partners is relatively common (Tallis, Eysenck, \& Mathews, 1992). We are aware of no research examining the link between perceptions of control in relationships and worry. Given the lack of research on this issue, we focused on worry that a relationship could end, rather than on more mundane day-to-day worries. Relationships can end for a variety of reasons including choice, disputes, geographic relocation, and death. Rusbult and colleagues argue that individuals think about, and behave differently, in relationships when they perceive that such relationships have a higher likelihood of ending (Rusbult, 1980; Rusbult, Zembrodt, \& Gunn, 1982). We expected increased worry to be associated with decreased perceptions of control.

\section{Differences in Perceptions of Control Over Different Types of Relationships}

Just as there is variability across life domains, there may be variability in perceptions of control over different relationships. To date, however, most research examines individuals' perceptions of control in the social domain by asking about their social networks in general (e.g., Bisconti \& Bergeman, 1999), or by aggregating their perceptions of control across multiple relationships (e.g., Seeman, Unger, McAvay, \& Mendes de Leon, 1999). The few studies that have differentiated across relationships have focused primarily on nuclear family ties (Cook, 1993; Lachman \& Weaver, 1998). Certainly, nuclear family ties play an important role in individuals' lives, and individuals are highly invested in these ties (Fingerman \& Hay, 2002). The present study examined perceptions of control 
over nuclear family ties (e.g., spouse, sibling, children, parent). Individuals, however, also consider extended family members and non-kin relationships to be important in their lives (Fingerman \& Hay). Thus, we included two additional relationship categories that have been examined in other relationship research (Okun \& Keith, 1998; Walen \& Lachman, 2000): other family ties (e.g., grandchildren, aunts, cousins) and non-family ties (e.g., friends, co-workers).

There are a number of reasons to examine how perceptions of control vary across these types of relationships. First, the emotional qualities of relationships differ (Antonucci \& Akiyama, 1987; Fingerman \& Birditt, 2003); for example, adults typically feel emotionally closer with their spouses and children than with many non-kin ties (e.g., coworkers, neighbors). Second, some relationships are ascribed, while others are chosen (Litwak, 1989); friendships are largely chosen, in contrast to most family ties. Finally, at different stages of life, individuals have access to different social partners (Fingerman \& Birditt, 2003; Kahn \& Antonucci, 1980). For example, older adults are more likely to have grandchildren and less likely to have living parents than are adolescents. These differences may be relevant to individuals' perceptions of control in relationships.

Clearly, however, placing relationships into such broad categories is not ideal. Nor do the characteristics of relationships clearly map onto these broad categories. For example, some adults may have close ties with their extended families. As well, many non-family ties are involuntary (e.g., ties with coworkers, neighbors). Despite the shortcomings inherent to using such broad categories, this approach contributes to an understanding of perceptions of control in relationships beyond nuclear family ties. Given the paucity of research examining control in specific relationships, it is not possible to provide explicit hypotheses about variations in control across relationships.

\section{Age Differences in Perceptions of Control in Relationships}

Research examining individuals' perceptions of control over their personal relationships is sparse. Some research and theory suggests, however, that adults may perceive greater control over their relationships as they grow older. First, older adults report fewer interpersonal problems with their social partners than do younger adults across a wide range of relationships (Bedford, 1989; Fingerman, 1996; Ingersoll-Dayton, Morgan, \& Antonucci, 1997; Levenson, Carstensen, \& Gottman, 1993; Okun \& Keith, 1998; Rook, 1992). This reduction in interpersonal problems may reflect that older adults appear better able to regulate their emotions in the context of relationships ( Carstensen, Gross, \& Fung, 1997; Carstensen, Isaacowitz, \& Charles, 1999). Similarly, older adults appear to worry less about their social partners than do younger adults (Doucet, Ladouceur, Freeston, \& Dugas, 1998; Johnson \& Barer, 1997). Given the relative lack of problems and 
worry in their interpersonal ties, older adults may feel more in control of their relationships than do younger adults.

In addition, according to socioemotional selectivity theory, individuals let go of emotionally unrewarding relationships as they approach the end of life in favor of greater investment in their remaining rewarding relationships (Carstensen, 1992; Lang, 2000). Through this process, adults may actively select relationships in ways that enhance their sense of control (e.g., selecting highly positive relationships over more problematic ones). Not all age-associated changes in social networks are the result of voluntary selection, however. As discussed, older adults have access to different relationships than do younger adults (Fingerman \& Birditt, 2003; Kahn \& Antonucci, 1980). Most notably, older adults are more likely than younger adults to have experienced the death of important social partners such as spouses, parents, and even children (Johnson \& Barer, 1997; O'Bryant \& Hansson, 1995). Indeed, in their qualitative study of European American and African American oldest-old adults, Johnson and Barer reported that older adults described difficulties maintaining social ties in the face of death, illness, and geographic relocations. Thus, the oldest-old may perceive diminished control in various areas of life, including their relationships.

Currently, a drawback of existing studies is that they lack a sufficiently wide age range to permit a thorough consideration of age differences in perceptions of control in relationships. Thus, in addition to considering perceptions of control in multiple relationships, this study considers perceptions of control in relationships among individuals ranging from adolescence through oldest-old age.

\section{Perceptions of Control in Relationships and in General}

As discussed earlier, theorists have suggested that individuals' perceptions of control in relationships contribute to their general perceptions of control (e.g., Bandura, 1997; Krause, 1995; Levenson, 1973a; Skinner, 1992). Indeed, Lachman and Weaver (1998) found individuals' perceptions of mastery were moderately associated with their perceptions of control in their relationships with spouses and children. Nurmi et al. (1992) examined adults' perceived control in relationships with children, and found similar results. However, they also found adults' perceptions of control in relationships with "other family" were unrelated to their general perceptions of control.

Inconsistent findings regarding the association between perceptions of control in general and perceptions of control in relationships could reflect differences in relationship salience. Theorists have argued that individuals' perceptions of control in specific areas of life (e.g., work, education) influence their general perceptions of control in varying degrees, depending on how important each area of life is to them (Brandstädter \& Rothermund, 1994; Nurmi et al., 1992). 
Consequently, individuals' perceptions of control within their most important relationships are more likely to be associated with their general perceptions of control than would be their perceptions of control in less important relationships. In this study, therefore, we focused on emotionally salient relationshipsindividuals' closest and most problematic ties.

In sum, we consider four issues: 1) whether characteristics of relationships are associated with perceptions of control in relationships; 2) whether individuals perceive different levels of control across their relationships (e.g., spouse, sibling); 3) age differences in individuals' perceptions of control in relationships; and 4) the association between perceptions of control in relationships and general perceptions of control.

\section{METHOD}

\section{Participants}

The sample consisted of 187 individuals ranging in age from 13 to 99 who had participated in a larger study of social ties (Birditt \& Fingerman, 2003; Fingerman $\&$ Birditt, 2003). Participants were recruited through newspaper advertisements, word of mouth, social gatherings, and community groups.

Participants were approximately evenly distributed by gender (101 women and 86 men) across five age groups: adolescents (13 to 16 years: $M=14.77$, $S D=1.01$ ), young-adults (20 to 29 years: $M=23.98, S D=2.78$ ), middle-aged adults (40 to 49 years: $M=45.03, S D=2.59$ ), young-old adults (60 to 69 years: $M=64.99, S D=2.93$ ), and the oldest-old (80 years and older: $M=83.71$, $S D=4.12$ ). These age groups were selected to approximate distinct stages of life. The sample was relatively homogeneous, but it is representative of the county in which data were collected (Centre County, Pennsylvania). Table 1 presents background information on the participants by age group; the sample is described in greater detail elsewhere (Fingerman \& Birditt, 2003).

\section{Measures}

Participants completed one- to two-hour interviews in their homes or at the study site. Following the interview, participants completed a short questionnaire. The participants responded to a variety of questions about themselves (e.g., background information, mental and physical health). We refer to these variables as participant-level variables. In addition, participants provided information on their interpersonal relationships. We refer to these variables as relationship-level variables. ANOVAs and Tukey's post-hoc tests were used to estimate age differences in independent variables. 
Table 1. Characteristics of Participants by Age Group

\begin{tabular}{|c|c|c|c|c|c|}
\hline & $\begin{array}{l}\text { Adolescent } \\
\quad(n=39)\end{array}$ & $\begin{array}{l}\text { Young-adult } \\
\quad(n=40)\end{array}$ & $\begin{array}{l}\text { Middle-aged } \\
\quad(n=34)\end{array}$ & $\begin{array}{l}\text { Young-old } \\
(n=39)\end{array}$ & $\begin{array}{l}\text { Oldest-old } \\
(n=35)\end{array}$ \\
\hline \multicolumn{6}{|l|}{ Means } \\
\hline Age (years) & $\begin{array}{l}14.77 \\
(1.01)\end{array}$ & $\begin{array}{l}23.98 \\
(2.78)\end{array}$ & $\begin{array}{l}45.03 \\
(2.59)\end{array}$ & $\begin{array}{l}64.99 \\
(2.93)\end{array}$ & $\begin{array}{c}83.71 \\
(4.12)\end{array}$ \\
\hline Education $^{a}$ & $\begin{array}{l}1.79 \\
(0.41)\end{array}$ & $\begin{array}{c}4.55 \\
(0.78)\end{array}$ & $\begin{array}{c}4.94 \\
(1.39)\end{array}$ & $\begin{array}{c}5.05 \\
(1.37)\end{array}$ & $\begin{array}{c}4.97 \\
(1.67)\end{array}$ \\
\hline \multicolumn{6}{|l|}{$\begin{array}{l}\text { General perceptions } \\
\text { of control }\end{array}$} \\
\hline Internal control & $\begin{array}{c}34.38 \\
(4.13)\end{array}$ & $\begin{array}{c}33.54 \\
(6.27)\end{array}$ & $\begin{array}{l}34.36 \\
(4.54)\end{array}$ & $\begin{array}{l}35.05 \\
(4.96)\end{array}$ & $\begin{array}{c}32.52 \\
(5.60)\end{array}$ \\
\hline Powerful others & $\begin{array}{l}18.51 \\
(9.13)\end{array}$ & $\begin{array}{l}15.26 \\
(7.78)\end{array}$ & $\begin{array}{l}14.18 \\
(8.33)\end{array}$ & $\begin{array}{l}14.76 \\
(7.74)\end{array}$ & $\begin{array}{l}15.91 \\
(10.18)\end{array}$ \\
\hline Chance & $\begin{array}{l}20.87 \\
(6.14)\end{array}$ & $\begin{array}{l}19.10 \\
(6.26)\end{array}$ & $\begin{array}{l}17.64 \\
(7.77)\end{array}$ & $\begin{array}{l}17.26 \\
(7.09)\end{array}$ & $\begin{array}{l}20.97 \\
(8.87)\end{array}$ \\
\hline Self-rated health & $\begin{array}{l}77.95 \\
(15.52)\end{array}$ & $\begin{array}{c}79.10 \\
(14.19)\end{array}$ & $\begin{array}{l}84.06 \\
(14.15)\end{array}$ & $\begin{array}{c}77.95 \\
(16.89)\end{array}$ & $\begin{array}{c}79.89 \\
(14.57)\end{array}$ \\
\hline Depressive symptoms & $\begin{array}{l}15.64 \\
(4.73)\end{array}$ & $\begin{array}{l}14.53 \\
(4.87)\end{array}$ & $\begin{array}{l}12.21 \\
(3.91)\end{array}$ & $\begin{array}{c}11.79 \\
(3.07)\end{array}$ & $\begin{array}{l}12.51 \\
(3.38)\end{array}$ \\
\hline \multicolumn{6}{|l|}{ Proportions } \\
\hline Female & 0.56 & 0.50 & 0.50 & 0.49 & 0.57 \\
\hline Married/remarried & 0.00 & 0.20 & 0.67 & 0.51 & 0.34 \\
\hline Widowed & 0.00 & 0.00 & 0.00 & 0.26 & 0.63 \\
\hline Divorced & 0.00 & 0.03 & 0.18 & 0.23 & 0.00 \\
\hline Single & 1.00 & 0.77 & 0.15 & 0.00 & 0.03 \\
\hline
\end{tabular}

$a_{1}=$ grade school, 2 = some high school, 3 = high school, $4=$ some college, $5=$ college, $6=$ masters degree, $7=$ advanced degree.

Note: Values enclosed in parentheses represent standard deviations.

\section{Participant-Level Variables}

To assess general perceptions of control, participants completed Levenson's (1973b, 1981) Locus of Control measure. The scale consists of three eight-item subscales that assess whether individuals believe events are within their control (internality) or that external forces control events (powerful others and chance). Participants indicated their agreement with items on a 7-point scale from -3 (strongly disagree) to 3 (strongly agree). The internal consistency of both external 
subscales was high (greater than $\alpha=0.70$ ), however, the internal consistency of the internality subscale was low $(\alpha=0.50)$. Examination by age group revealed that the internal consistency of the internality subscale was particularly low among the adolescents, middle-aged adults, and oldest-old adults. Thus, this subscale does not clearly represent a unidimensional construct at any point in adulthood. Consequently, any significant results regarding the internality subscale should be interpreted with caution. Participants' mean scores were in keeping with past research (e.g., Lachman \& Leff, 1989; Levenson, 1981; also see Table 1). Also consistent with previous research (Lachman, 1986), there were no significant age differences in scores on these subscales.

\section{Covariates}

Previous research has suggested a number of participant-level characteristics that may vary by age are also associated with perceptions of control and may, therefore, confound analyses of the effects of age. These characteristics were treated as covariates in analyses and include education and both self-rated and psychological health (Gatz \& Karel, 1993; Mirowsky, 1995; Perrig-Chiello, Perrig, \& Staehelin, 1999; Rodin, 1986; Wolinksy \& Stump, 1996). Research findings regarding gender differences in perceptions of control are mixed (Gatz \& Karel, 1993; Huyck, 1991). Thus, we also included gender as a covariate.

Respondents indicated the highest level of education they achieved from $1=$ grade school to $7=$ advanced degree (see Table 1). As expected, teenagers had significantly less education than all other age groups, $F(4,186)=52.0, p<0.01$.

Participants also completed the MOS-36 five-item scale for general health perceptions (Ware \& Sherbourne, 1992). For each item, respondents used a 5 -point scale. The first item assesses general health using a scale of 1 (excellent) to 5 (poor); the subsequent items ask how true four statements are of the respondent from 1 (definitely true) to 5 (definitely false). Where necessary, responses were recoded so that higher scores indicate better health. Participants' scores on the MOS-36 general health subscale are expressed as a percentage of the total possible score. Participants' scores (see Table 1) and the internal consistency of the measure (coefficient $\alpha=0.74$ ) were in keeping with past research (e.g., McHorney, Kosinski, \& Ware, 1994). No significant age differences were found in participants' ratings of subjective health.

Depressive symptoms were assessed with a nine-item short form of the Center for Epidemiological Studies Depression scale (CES-D; Radloff, 1977). A variety of CES-D short forms exist (e.g., Earle, Smith, Harris, \& Longino, 1998; Kohout, Berkman, Evans, \& Cornoni-Huntley, 1993; Townsend, Miller, \& Guo, 2001; Turvey, Wallace, \& Herzog, 1999). For this study, nine items were selected from the original CES-D scale (Radloff, 1977) to represent a balance of somatic/vegetative and affective items. The original 4-point scale where $1=$ rarely and $4=$ most of the time was used. The internal consistency of this unique CES-D 
short-form was within the range found with other published short forms (coefficient $\alpha=0.78$; Kohout et al. 1993; Townsend et al., 2001) and the average CES-D score was low (see Table 1). Significant age differences in CES-D scores emerged, $F(4,186)=6.35, p<0.01$, with younger participants endorsing more depressive symptoms than older adults.

\section{Relationship-Level Variables}

A variety of relationship-level characteristics were also considered. To capture social ties of varying quality, participants were asked to diagram two social networks. First, they nominated close social partners using Kahn and Antonucci's (1980) social network questionnaire. In the innermost circle, participants placed their closest relationships; in the second and third circles, they placed social partners of lesser importance. Then, participants nominated problematic social partners using an adaptation of this measure (Fingerman \& Birditt, 2003). In the innermost circle, participants placed individuals who bothered them the most. In the second and third circles, they placed social partners who bothered them to a lesser degree. Participants could nominate the same or different social partners in the two networks.

Participants provided detailed information on the three closest and three most problematic social partners they nominated. Given that the two networks could overlap, participants provided detailed information on three to six relationships $(M=4.96, S D=1.02)$. Two issues should be noted with this procedure. First, this assessment does not represent the full range of relationships in individuals' social networks. This procedure, however, captures relationships of varying quality. Second, participants described relationships that were emotionally salient to them, rather than rating a predefined list of specific relationships (e.g., spouse, parent). Ratings of specific relationships could introduce age biases, because relationships are not necessarily equally available or salient to individuals across the life course. Of course, it would be ideal to have participants provide detailed information on all their social partners; however, asking participants to do so would have constituted a considerable burden and could have introduced response set biases.

Participants rated their perceptions of control over the quality of these relationships on a 5-point scale $(1=$ almost no control to $5=$ a great deal of control $)$. The item was worded as such to ensure participants did not interpret "control" to mean exerting control over, or manipulating, their social partner. Rather, we were interested in the participants' sense that the quality of the relationship, as a whole, was under their influence. Seeman et al. (1999) assessed interpersonal self-efficacy in adults' relationships with family, friends, and spouses in a similar vein, asking whether they could ensure each of those relationships were "as satisfying and rewarding as I would like" (p. P216). Time constraints precluded the use of multiple items to assess control over each relationship. Although not 
ideal, single-item ratings of control in relationships have been used successfully in the past (Lachman \& Weaver, 1998). Indeed, participants did distinguish among their relationships using the one-item ratings. For example, the average control participants felt in relationships from the close circle was $3.86(S D=1.12)$, while the average control felt in relationships from the problematic circle only was $2.65(S D=1.13)$. On average, participants felt moderately in control of their relationships (see Table 2).

Participants also provided information on the relationship type. As mentioned previously, relationships were placed into one of six relationship categories: spouse, parent, child, siblings, other family, and non-family. Table 2 presents the proportion of relationships falling into these categories for each age group (i.e., within age groups, they sum to one). Age differences in the relationships participants discussed were consistent with individuals' life stages. For example, no adolescents discussed spouses, but many older adults did.

Finally, using Likert scales, participants rated the quality of each relationship $(1=$ poor, $7=$ outstanding $)$ and how much they worry about each relationship

Table 2. Features of Participants' Relationships and Social Networks by Age Group

\begin{tabular}{|c|c|c|c|c|c|}
\hline & $\begin{array}{l}\text { Adolescent } \\
(n=39)\end{array}$ & $\begin{array}{l}\text { Young-adult } \\
\quad(n=40)\end{array}$ & $\begin{array}{l}\text { Middle-aged } \\
\quad(n=34)\end{array}$ & $\begin{array}{l}\text { Young-old } \\
(n=39)\end{array}$ & $\begin{array}{c}\text { Oldest-old } \\
(n=35)\end{array}$ \\
\hline Mean control ${ }^{a}$ & $\begin{array}{c}3.48 \\
(1.25)\end{array}$ & $\begin{array}{l}3.39 \\
(1.21)\end{array}$ & $\begin{array}{c}3.54 \\
(1.16)\end{array}$ & $\begin{array}{c}3.38 \\
(1.21)\end{array}$ & $\begin{array}{c}3.20 \\
(1.52)\end{array}$ \\
\hline Mean worry ${ }^{b}$ & $\begin{array}{c}2.07 \\
(1.25)\end{array}$ & $\begin{array}{c}2.00 \\
(1.27)\end{array}$ & $\begin{array}{c}1.73 \\
(1.06)\end{array}$ & $\begin{array}{c}1.70 \\
(1.11)\end{array}$ & $\begin{array}{l}1.34 \\
(0.99)\end{array}$ \\
\hline Mean quality ${ }^{c}$ & $\begin{array}{c}4.20 \\
(1.96)\end{array}$ & $\begin{array}{c}4.45 \\
(1.87)\end{array}$ & $\begin{array}{l}4.22 \\
(2.11)\end{array}$ & $\begin{array}{c}4.41 \\
(1.92)\end{array}$ & $\begin{array}{c}4.58 \\
(1.76)\end{array}$ \\
\hline \multicolumn{6}{|c|}{$\begin{array}{l}\text { Type of relationship } \\
\text { (expressed as } \\
\text { proportions) }\end{array}$} \\
\hline Spouse & - & 0.04 & 0.14 & 0.10 & 0.08 \\
\hline Child & - & 0.02 & 0.23 & 0.34 & 0.44 \\
\hline Parents & 0.35 & 0.29 & 0.10 & 0.03 & - \\
\hline Siblings & 0.16 & 0.12 & 0.08 & 0.03 & 0.03 \\
\hline Other family & 0.03 & 0.09 & 0.07 & 0.17 & 0.15 \\
\hline Non-family & 0.46 & 0.44 & 0.38 & 0.33 & 0.30 \\
\hline
\end{tabular}

$a_{1}=$ almost no control, $5=$ a great deal of control

$b_{1}=$ not at all, $5=$ a great deal

$c_{1}=$ poor, 7 = outstanding

Note: Values enclosed in parentheses represent standard deviations. 
ending $(1=$ not at all, $5=$ a great deal $)$. Participants' ratings of relationships quality ranged from 1 to 7 ; on average, participants felt their relationships were of moderately high quality (see Table 2). An ANOVA revealed no significant age differences in average relationship quality. In general, participants did not worry a great deal about their relationships (see Table 2). An ANOVA, however, revealed significant age differences, with oldest-old participants worrying less about their relationships ending than either adolescents or young adults, $F(4,186)=5.39, p<0.01$.

\section{Data Analysis Strategy}

The 187 participants in the study provided detailed information on 927 relationships. Thus, for each participant, there was data for multiple relationships. Multilevel models were used to take into account this non-independence of the data. The data were analyzed using SAS Proc Mixed (SAS Institute, 2000). Proc Mixed allowed both participant-level and relationship-level data to be assessed in the same equation; Proc Mixed also allowed both fixed and random effects to be included in models (for a full discussion of multilevel models see Kenny, Bolger, \& Kashy, 2002; Singer, 1998).

In addition to accounting for the structure of the data, multilevel models allowed us to examine the four issues of interest parsimoniously in one complete model. Consequently, we did not examine our research questions in sequence, but rather addressed our research questions simultaneously. Age and general perceptions of control were included as upper-level, participant characteristics, while features of relationships and relationship type were included as lower-level, relationship characteristics. The full model was:

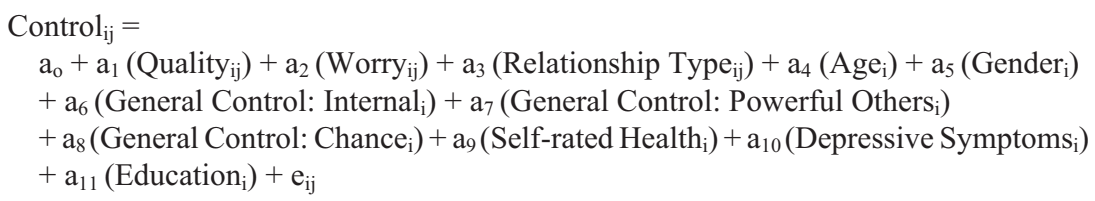

The outcome, Control $\mathrm{ij}_{\mathrm{ij}}$ - a relationship-level variable - is the amount of control participant i feels in relationship j. The relationship-level predictors Quality ${ }_{\mathrm{ij}}$, Worry $_{\mathrm{ij}}$, and Relationship Type $\mathrm{i}_{\mathrm{ij}}$ are the ratings of quality and worry participant $\mathrm{i}$ reported for relationship $\mathrm{j}$ and the type of relationship $\mathrm{j}$ is. The participant-level predictors include age $\left(\mathrm{Age}_{\mathrm{i}}\right)$ and general perceptions of control (General Control: Internal $_{i}$, General Control: Powerful Others ${ }_{i}$, General Control: Chance $\left.{ }_{i}\right)$. The remaining participant-level variables are covariates. The $\beta$ weights, represented by $a_{1}, a_{2}, a_{3}$, etc., reflect the effect of each predictor on perceptions of control in relationships across all participants (e.g., $a_{1}$ is the estimated effect of relationship quality on perceptions of control in all relationships for all participants).

In these equations, all independent variables are considered fixed. Participants, however, are a subset of all individuals who could have participated in the study, 
and therefore are random. Two error terms are presented in tables. The covariance (CS) is the error between participants, while the residual (RES) is the error within participants. The Proc Mixed procedure (SAS Institute, 2000) corrects for the $\mathrm{CS}$ and the only remaining error in the model is the RES.

\section{RESULTS}

First, the pattern of correlations between independent variables was examined to determine whether certain variables appeared to tap the same construct. The two external control subscales were highly correlated $(r=0.65, p<0.01)$; however, none of the other variables exhibited correlations greater than 0.33 .

We also examined the associations of the covariates with perceptions of control in relationships (see Table 3). Only one covariate-individuals' general perceptions of health - was significantly associated with the outcome of interest. Individuals with higher perceived health felt more in control of their relationships. For parsimony, the covariates of gender, depressive symptoms, and education were not included in subsequent models.

\section{Multilevel Models}

Prior to estimating the model, all continuous variables were centered on the grand mean to facilitate interpretation of the estimates (see Kenny et al., 2002). We considered the four research issues of interest in one inclusive model that contained the relationship-level characteristics of interest-features of relationships and type of relationship - and the participant-level characteristics of interest - age and general perceptions of control.

Table 3. Multilevel Model Estimating the Influence of Participant-Level Covariates on Perceptions of Control in Relationships

\begin{tabular}{lcc}
\hline Fixed effects & $B$ & $S E$ \\
\hline Intercept & 3.40 & 0.08 \\
Gender & & \\
$\quad$ Female & 0.01 & 0.11 \\
$\quad$ Male & - & - \\
Depressive symptoms (CES-D) & -0.02 & 0.01 \\
General perceptions of health & 0.01 & $0.00^{*}$ \\
Education & -0.03 & 0.03 \\
\hline
\end{tabular}

Notes: $B=$ unstandardized regression coefficient. Observations $=919, N=187$.

$\mathrm{CS}=0.29, \mathrm{RES}=1.30$

${ }^{*} p<0.01$. 
Table 4 shows the results of this model. As expected, relationship-level characteristics and relationship type were associated with perceptions of control within relationships. Specifically, individuals felt more control in high-quality relationships and relationships that were less worrisome. As well, Tukey's post-hoc tests revealed that individuals felt more control in their marital ties than in other types of relationships.

Of the two individual-level characteristics included-age and general perceptions of control — only age was a significant predictor of perceptions of control

Table 4. Multilevel Model Estimating the Influence of Age, General Perceptions of Control, and Features of Relationships on Perceptions of Control in Relationships

\begin{tabular}{|c|c|c|}
\hline Fixed effects & $B$ & SE \\
\hline Intercept & 2.98 & 0.15 \\
\hline \multicolumn{3}{|l|}{ Participant-level characteristics } \\
\hline \multicolumn{3}{|l|}{ Age } \\
\hline Adolescent & 0.62 & $0.18 * \star$ \\
\hline Young adult & 0.36 & $0.18^{\star}$ \\
\hline Middle-aged adult & 0.49 & $0.18 * \star$ \\
\hline Young-old adult & 0.31 & 0.17 \\
\hline Oldest-old adult & - & - \\
\hline \multicolumn{3}{|l|}{ General perceptions of control } \\
\hline Internality & -0.02 & 0.01 \\
\hline Powerful others & 0.00 & 0.01 \\
\hline Chance & 0.00 & 0.01 \\
\hline General perceptions of health & 0.01 & 0.00 \\
\hline \multicolumn{3}{|l|}{ Relationship-level characteristics } \\
\hline Relationship quality & 0.36 & $0.02^{\star \star *}$ \\
\hline Relationship worry & -0.11 & $0.03^{\star *}$ \\
\hline \multicolumn{3}{|l|}{ Type of relationship } \\
\hline Spouse & 0.50 & $0.13^{\star *}$ \\
\hline Child & 0.06 & 0.11 \\
\hline Parent & -0.04 & 0.12 \\
\hline Sibling & -0.01 & 0.10 \\
\hline Other family & -0.14 & 0.13 \\
\hline Non-family & - & - \\
\hline
\end{tabular}

Notes: $B=$ unstandardized regression coefficient. Observations $=876, N=178$. $\mathrm{CS}=0.29, \mathrm{RES}=0.76$ ${ }^{*} p<0.05 .{ }^{* *} p<0.001 .{ }^{* * *} p<0.0001$. 
in relationships. Contrary to our hypotheses, Tukey's post-hoc tests indicated that adolescent and middle-aged adults felt more control over their relationships than the oldest-old.

\section{Post-Hoc Analyses}

To understand whether age differences in perceptions of control stemmed from age differences in perceptions of control within specific relationships, we estimated post-hoc analyses of perceptions of control within the six categories of relationships. Given that not all age groups discussed each relationship (e.g., adolescents had no spouses), interpreting relationship type $\times$ age group interactions within a multilevel model was complex. Therefore, we used a betweenperson analysis strategy and performed an ANOVA for each relationship type (e.g., spouse, parent, sibling). In relationship categories other than spouse, where a participant could discuss more than one relationship (e.g., two siblings), we calculated the average control, quality, and worry he/she felt in those relationships. This procedure reduces the within-person variability; however, given that the variable of interest in these analyses is participant-level (i.e., age), we felt a between-person analysis strategy was sufficient. Furthermore, given that we were only aggregating within relationship categories, we were typically averaging across a small number of relationships. Indeed, among participants who discussed particular relationships, in all relationship categories except non-family members, the average number of relationships discussed by the participants fell between one and two. For instance, participants who discussed siblings discussed on average 1.21 $(S D=0.48)$ siblings. Among participants who discussed non-family members, they discussed, on average, $2.43(S D=1.21)$ nonfamily members.

To be included in the analyses, at least 10 individuals within an age group had to discuss a given relationship. For example, no adolescents discussed spouses and only eight young-adults did. Therefore, only middle-aged, young-old, and oldest-old adults were included in analyses of age differences in adults' perceptions of control over spouses. We included relationship quality and worry as covariates in these analyses.

No significant age differences emerged for perceptions of control over spouses (contrasting middle-aged, young-old, and oldest-old adults), siblings (contrasting adolescents, young-adults, and middle-aged adults), other family (contrasting young-adults, middle-aged, young-old, and oldest-old), and non-family (contrasting all age groups). Significant age differences in perceptions of control were found in relationships with parents and children. Table 5 shows the mean perceived control over children and parents by age group. Consistent with prior studies (e.g., Lachman \& Weaver, 1998), older adults perceived less control over their children than did younger adults. Similarly, older adults felt less control over their relationships with their parents than did younger adults. These findings 
Table 5. Significant ANOVAs for Mean Perceptions of Control Within Relationship Types

\begin{tabular}{lll}
\hline Age group & $M$ & $S E$ \\
\hline With children, $F(2,169)=6.95, p<0.001$ & & \\
Middle-aged adults & 4.00 & 0.17 \\
Young-old & 3.73 & 0.13 \\
Oldest-old & 3.21 & 0.15 \\
& & \\
With parents, $F(2,144)=4.45, p<0.05$ & & \\
Adolescents & 4.03 & 0.18 \\
Young adult & 3.25 & 0.17 \\
Middle-aged & 3.63 & 0.27 \\
\hline
\end{tabular}

suggest there may be something unique to the parent-child tie in terms of how perceptions of control shift across the lifespan. Potential reasons for, and implications of, these findings are discussed next.

\section{DISCUSSION}

This study provides a unique look at individuals' perceptions of control in relationships. We examined four related issues: 1) whether characteristics of relationships were associated with individuals' perceptions of control in those relationships; 2) whether individuals' perceptions of control varied across different types of relationships; 3) age differences in individuals' perceptions of control in the social domain; and 4) whether individuals' perceptions of control in relationships reflected their general perceptions of control. The pattern of findings suggests that characteristics of relationships (i.e., within-person differences such as relationship quality) are more relevant to understanding perceptions of control in relationships than are individual characteristics (i.e., between-person differences such as general perceptions of control).

\section{Characteristics of Relationships, Relationship-Type, and Perceptions of Control in Relationships}

Our first two questions examined whether individuals' perceptions of control over their relationships depended upon features of relationships including quality, worry, and relationship type. Analyses reveal that the quality of a given relationship is the most important predictor of an individual's perception of control over that relationship. This finding is consistent with previous studies (Cook, 1993; Lachman \& Weaver, 1998; Martini et al., 2001). Prior studies, however, assessed perceptions of control in a limited number of nuclear family ties. The 
present study provides evidence that relationship quality predicts perceptions of control in many interpersonal ties including nuclear family ties, extended family ties, and non-kin relationships.

As hypothesized, worry was also associated with perceptions of control in relationships. Consistent with past research (Tallis et al., 1992), older adults worried less about their relationships than younger adults. With respect to perceptions of control, the more individuals worried about a relationship, the less control they felt over that relationship. In this study, we assessed a specific type of worry - worry that the relationship may end. As discussed, relationships may end for a variety of reasons. Worries about relationships, however, are not limited to worrying about relationships ending. For example, a parent worrying about their child's peers or an individual worrying about their romantic partner's approval are not necessarily concerned about the relationship ending. Consequently, future research should consider other relationship worries. Worrying about disagreements with social partners or the lifestyles of social partners may, indeed, be more common than worrying about the end of relationships, and may also be linked with decreased perceptions of control within the relationship.

We also examined different types of relationships and found that individuals felt more control in relationships with spouses than in other relationships. No other within-individual differences in perceptions of control due to relationship type were apparent. Researchers have commented on the unique nature of marital ties. Cook (1993) noted that individuals typically perceive high levels of control and relinquish a great deal of control in marriages. Few other relationships are characterized by such a high degree of intimacy and involvement; this high involvement and "give-and-take" may contribute to higher perceived control than is felt in other relationships.

\section{Age Differences in Perceptions of Control in Relationships}

Analyses revealed age differences in perceptions of control in relationships. However, these age differences were small, and it was only oldest-old adults who perceived less control than the other age groups. Johnson and Barer (1997) suggested the oldest-old find it difficult to maintain their sense of control as a result of declining health, geographic relocation, and the deaths of family members and friends. Our findings do indicate that perceptions of health are associated with perceptions of control in relationships; however, age differences remain after perceptions of health have been considered. Unfortunately, we did not obtain information on deaths or relocations of social partners. Nonetheless, our results are consistent with the view that deaths, particularly of spouses, could be an important factor in age-associated decreases in perceptions of control in relationships. The adults in our study perceived very high levels of control in their marital relationships; however, the majority of the oldest-old adults in our study 
were widowed. It is possible that the lower levels of perceived control over relationships among the oldest-old reflects the loss of a relationship that, throughout much of adulthood, was an important source of perceived control. Older adults' remaining relationships may be close and supportive; however, they may not be able to compensate for the loss of the spousal tie in terms of perceived control.

In an attempt to further our understanding of the factors that could underlie age differences in perceptions of control, we examined age differences in perceived control within specific relationships independent of the effects of relationship quality or worry. No age differences in perceptions of control over ties with spouses, siblings, extended family, or non-family were observed. Parent-child relationships, however, were an exception. In comparisons involving adolescents, young-adults, and middle-aged adults, younger individuals felt more control in relationships with their parents. Similarly, in comparisons of middle-aged, young-old, and oldest-old adults, younger individuals felt more control over relationships with their children. This pattern of findings suggests two things. First, unlike other relationships, the parent-child relationship may undergo shifts across the lifespan that result in changes in perceived control. Second, the highest levels of perceived control may be experienced in this relationship when both parties are younger (i.e., when parents and children are most likely to be living in the same households and interacting with one another on a daily basis). Indeed, these age differences in perceived control may be as much a reflection of the age of the social partner as the participant themselves. Age-associated changes in perceptions of control in relationships with children, coupled with the loss of spouses, may explain the lower perceptions of control that the oldest-old adults experienced in their relationships.

\section{General Perceptions of Control and Perceptions of Control in Relationships}

The final issue we considered was whether there was a link between perceptions of control in relationships and general perceptions of control. Notably, we found no evidence for such an association. Past research suggests that individuals' perceptions of control in relationships and relationship satisfaction are moderately associated with their perceptions of mastery (Huyck, 1991; Lachman \& Weaver, 1998). Theorists have argued that individuals' perceptions of control in specific areas of life (e.g., work, relationships) are associated with their general perceptions of control when an area of life is particularly important to them (Brandstädter \& Rothermund, 1994; Nurmi et al., 1992). Yet, we assessed emotionally salient relationships in this study and found no association. Our discrepant findings may reflect the measure we used to assess general control. Unlike mastery, Levenson's (1973b, 1981) measure of control does not assess whether participants feel they have the skills needed to capitalize on the controllability of events. This difference 
may appear subtle; however, it could underlie our discrepant findings given the importance of such skills in negotiating interpersonal relationships (Christiansen \& Shenk, 1991; Markman, Jamieson, \& Floyd, 1983). Alternatively, our lack of findings may reflect the poor internal consistency of the Levenson measure of control, which has also been found in other studies (e.g., Lumpkin, 1998; Pankow, 1996; Shewchuk, Foelker, \& Niederehe, 1990). Given that research increasingly suggests that individuals' perceptions of control are differentiated, it is not necessarily surprising that there is little evidence that this measure of general control represents a unidimensional construct. Nonetheless, the poor internal consistency of this scale is a limitation of this study. Indeed, it is possible that no support was found for the hypothesis that perceptions of control in relationships would be associated with general perceptions of control, because the measure of general perceptions of control was not ideal.

In sum, our findings indicate that individuals' perceptions of control in their relationships are not trait-like; within individuals, perceptions of control vary across relationships. Throughout adulthood, individuals' perceptions of control in relationships appear to be associated primarily with features of the relationships themselves - their quality, the type of relationship it is, and how much the individual is worried about the relationship ending. Nor do these perceptions vary dramatically across the life span. Indeed, age differences in perceptions of control in relationships appear to be limited to the oldest-old, and are not extreme.

\section{Suggestions for Future Research}

Although this study adds to a growing body of work on perceptions of control in the social domain, it is not without limitations. The primary limitations of this study include the use of single-item measures to assess perceptions of control in relationships, and most notably, the non-representativeness of the sample. Indeed, this sample was primarily Caucasian and from a rural area. Research on general perceptions of control, however, indicates that there are differences in perceptions of control, albeit slight, by ethnicity (e.g., Mirowsky, 1995; Wolinsky \& Stump, 1996). In previous studies examining perceptions of control in relationships, however, ethnicity has not been considered (e.g., Cook, 1993, 2001; Lachman \& Weaver, 1998; Martini et al., 2001). The possibility remains, therefore, that individuals' perceptions of control in relationships reflect their ethnicity. For example, research indicates that some Latino groups emphasize the importance of the extended family (Becerra, 1988; Leyendecker \& Lamb, 1999). Perceptions of control in extended family ties, therefore, could be higher among certain Latino groups. Future studies should attempt to include more diverse samples to determine whether perceptions of control in the social domain vary across ethnic and cultural groups.

In addition, this sample was not obtained through random methods. Thus, although it is representative of the county in which data was collected, the 
individuals who chose to participate in this study of social ties may differ from the larger population in important ways. For example, individuals who chose to participate may have been inclined to do so because they have higher-quality relationships than individuals who declined participation. Studies that recruit participants randomly could resolve such issues.

Ultimately, our findings suggest that an understanding of perceptions of control in relationships requires in-depth examination of relationship quality and worries. What happens in high-quality relationships that enhance individuals' perceptions of control? Similarly, are many types of relationship worries or only some types of worries associated with feeling out of control? A more complete understanding of the role of quality and worry in perceptions of control in relationships may be key to understanding perceptions of control in relationships across the life span.

\section{ACKNOWLEDGMENT}

The authors are grateful to Steven Zarit for comments on earlier versions of this article.

\section{REFERENCES}

Antonucci, T. C. (2001). Social relations: An examination of social networks, social supports, and sense of control. In K. W. Schaie \& J. Birren (Eds.), Handbook of the psychology of aging (pp. 427-453). Orlando, FL: Academic Press.

Antonucci, T. C., \& Akiyama, H. (1987). An examination of sex differences in social support among older men and women. Sex Roles, 17, 737-749.

Bandura, A. (1997). Self-efficacy: The exercise of control. New York: W. H. Freeman \& Co.

Becerra, R. M. (1988). The Mexican American family. In C. H. Mindel, R. W. Habenstein, \& R. Wright (Eds.), Ethnic families in America (pp. 141-159). Englewood Cliffs, NJ: Prentice-Hall.

Bedford, V. H. (1989). Sibling research in historical perspective: The discovery of a forgotten relationship. American Behavioral Scientist, 33, 6-18.

Berkman, L. F., Glass, T. Brissette, I., \& Seeman, T. E. (2000). From social integration to health: Durkheim in the new millennium. Social Science and Medicine, 51, 843-857.

Birditt, K. S., \& Fingerman, K. L. (2003). Age and gender differences in adults' emotional reactions to interpersonal problems. Journal of Gerontology: Psychological Sciences, 58B, P237-P245.

Bisconti, T. L., \& Bergeman, C. S. (1999). Perceived social control as a mediator of the relationships among social support, psychological well-being and perceived health. The Gerontologist, 39, 94-101.

Brandstädter, J., \& Rothermund, K. (1994). Self-percepts of control in middle and later adulthood: Buffering losses by rescaling goals. Psychology and Aging, 9, 265-273.

Carstensen, L. L. (1992). Social and emotional patterns in adulthood: Support for socioemotional selectivity theory. Psychology and Aging, 7, 331-338. 
Carstensen, L. L., Gross, J. J., \& Fung, H. H. (1997). The social context of emotional experience. In K. W. Schaie \& M. P. Lawton (Eds.), Annual review of gerontology and geriatrics (Vol. 17, pp. 325-352). New York: Springer.

Carstensen, L. L., Isaacowitz, D. M., \& Charles, S. T. (1999). Taking time seriously: A theory of socioemotional selectivity. American Psychologist, 54, 165-181.

Christensen, A., \& Shenk, J. L. (1991). Communication, conflict, and psychological distance in nondistressed, clinic, and divorcing couples. Journal of Consulting and Clinical Psychology, 59, 458-463.

Cook, W. L. (1993). Interdependence and the interpersonal sense of control: An analysis of family relationships. Journal of Personality and Social Psychology, 64, 587-601.

Cook, W. L. (2001). Interpersonal influence in family systems: A social relations model analysis. Child Development, 72, 1179-1197.

Doucet, C., Ladouceur, R., Freeston, M., \& Dugas, M. J. (1998). Thèmes d'inquiétudes et tendence à s'inquiéter chez les aînés [Worry themes and tendency to worry among the elderly]. Canadian Journal on Aging, 17, 361-371.

Earle, J. R., Smith, M. H., Harris, C. T., \& Longino, C. F., Jr. (1998). Women, marital status, \& symptoms of depression in a midlife national sample. Journal of Women and Aging, 10, 41-57.

Fingerman, K. L. (1996). Sources of tension in the aging mother and adult daughter relationship. Psychology and Aging, 11, 591-606.

Fingerman, K. L., \& Birditt, K. S. (2003). Do age differences in close and problematic family ties stem from the pool of available relatives? Journals of Gerontology: Psychological Sciences, 57B, P80-P87.

Fingerman, K. L., \& Hay, E. L. (2002). Searching under the streetlight?: Age biases in the personal and family relationships literature. Personal Relationships, 9, 415-433.

Freeston, M. H., Rheaume, J., Letarte, H., Dugas, M. J., \& Ladouceur, R. (1994). Why do people worry? Personality and Individual Differences, 17, 791-802.

Gatz, M., \& Karel, M. J. (1993). Individuals change in perceived control over 20 years. International Journal of Behavioral Development, 16, 305-322.

Huyck, M. H. (1991). Predicates of personal control among middle-aged and youngold men and women in middle America. International Journal of Aging and Human Development, 32, 261-275.

Ingersoll-Dayton, B., Morgan, D., \& Antonucci, T. (1997). The effects of positive and negative social exchanges on aging adults. Journals of Gerontology: Psychological Sciences, 52, S190-S199.

Johnson, C. L., \& Barer, B. M. (1997). Life beyond 85 years: The aura of survivorship. New York: Springer.

Kahn, R. L., \& Antonucci, T. C. (1980). Convoys over the life course: Attachment, roles, and social support. Life-Span Development and Behavior, 3, 253-286.

Kenny, D. A., Bolger, N., \& Kashy, D. A. (2002) Traditional methods for estimating multilevel models. In D. S. Moskowitz \& S. L. Hershberger (Eds.), Modeling intraindividual variability with repeated measures data: Methods and applications. Multivariate applications book series (pp. 1-24). Mahwah, NJ: Lawrence Erlbaum Associates.

Kohout, F. J., Berkman, L. F., Evans, D. A., \& Cornoni-Huntley, J. (1993). Two shorter forms of the CES-D depression symptoms index. Journal of Aging and Health, 5, 179-193. 
Krause, N. (1995). Social support and feelings of personal control in later life. In G. R. Pierce, B. Lakey, I. G., Sarason, \& B. R., Sarason (Eds.), Sourcebook for social support and personality (pp. 335-355). New York: Plenum Press.

Lachman, M. E. (1986). Locus of control in aging research: a case for multidimensional and domain-specific assessment. Journal of Psychology and Aging, 1, 34-40.

Lachman, M. E., \& Leff, R. (1989). Perceived control and intellectual functioning in the elderly: A 5-year longitudinal study. Developmental Psychology, 25, 722-728.

Lachman, M. E., \& Weaver, S. L. (1998). Sociodemographic variations in the sense of control by domain: Findings from the MacArthur studies of midlife. Psychology and Aging, 13, 553-562.

Lang, F. R. (2000). Endings and continuity of social relationships: Maximizing intrinsic benefits within personal networks when feeling near to death. Journal of Personal and Social Relationships, 17, 157-184.

Levenson, H. (1973a). Perceived parental antecedents of internal, powerful others, and chance locus of control orientations. Developmental Psychology, 9, 268-274.

Levenson, H. (1973b). Multidimensional locus of control in psychiatric patients. Journal of Consulting \& Clinical Psychology, 41, 397-404.

Levenson, H. (1981). Differentiation among internality, powerful others, and chance. In H. M. Lefcourt (Ed.), Research with the locus of control construct: Volume 1 assessment methods (pp. 15-63). New York: Academic Press.

Levenson, R. W., Carstensen, L. L., \& Gottman, J. M. (1993). Long-term marriage: Age, gender, and satisfaction. Psychology and Aging, 8, 301-313.

Leyendecker, B., \& Lamb, M. E. (1999). Latino families. In M. E. Lamb (Ed.), Parenting and child development in "nontraditional" families (pp. 247-262). Mahwah, NJ: Lawrence Erlbaum.

Litwak, E. (1989). Forms of friendships among older people in an industrial society. In R. Adams, \& R. Blieszner (Eds.), Older Adult Friendship: Structure and Process (pp. 65-88). CA: Sage.

Lumpkin, J. R. (1998). Establishing the validity of an abbreviated locus of control scale: Is a brief Levenson's scale any better? Psychological Reports, 63, 519-523.

Markman, H. J., Jamieson, K. J., \& Floyd, F. J. (1983). The assessment and modification of premarital relationships: Preliminary findings on the etiology and prevention of marital and family distress. Advances in Family Intervention, Assessment, and Theory, 3, 41-90.

Martini, T. S., Grusec, J. E., \& Bernardini, S. C. (2001). Effects of Interpersonal control, perspective taking, and attributions on older mothers' and adult daughters' satisfaction with their helping relationships. Journal of Family Psychology, 15, 688-705.

McHorney, C. A., Kosinski, M., \& Ware, J. E. (1994). Comparisons of the costs and quality of norms for the SF-36 health survey collected by mail versus telephone interview: Results from a national survey. Medical Care, 32, 551-567.

Mirowsky, J. (1995). Age and the sense of control. Social Psychology Quarterly, $58,31-43$.

Nurmi, J., Pulliainen, H., \& Salmelo-Aro, K. (1992). Age differences in adults' control beliefs related to life goals and concerns. Psychology and Aging, 7, 194-196.

O’Bryant, S. L., \& Hansson, R. O. (1995). Widowhood. In R. Blieszner \& V. H. Bedford (Eds.), Handbook of aging and the family (pp. 440-458). Westport, CT: Greenwood Press. 
Okun, M. A., \& Keith, V. M. (1998). Effects of positive and negative social exchanges with various sources on depressive symptoms in younger and older adults. Journals of Gerontology: Psychological Sciences, 53B, P4-P20.

Pankow, L. J. (1996). Applicability of the Levenson LoC Scale to the lives of geriatric nursing home residents. Journal of Psychology and Theology, 24, 323-333.

Perrig-Chiello, P., Perrig, W. G., \& Staehelin, H. B. (1999). Health control beliefs in old age relationship with subjective and objective health, and health behavior. Psychology, Health and Medicine, 4, 83-94.

Radloff, L. S. (1977). The CES-D Scale: A self-report depression scale for the general population. Applied Psychological Measurement, 1, 385-401.

Rodin, J. (1986). Aging and health: Effects of the sense of control. Science, 233, 1271-1276.

Rodin, J., \& Timko, C. (1992). Sense of control, aging, and health. In M. G. Ory, R. P. Abeles, \& P. D. Lipman (Eds.), Aging, health, and behavior (pp. 174-206). CA: Sage.

Rook, K. S. (1992). Detrimental aspects of social relationships: Taking stock of an emerging literature. In H. O. Veiel \& U. Baumann (Eds.), The meaning and measurement of social support (pp. 157-169). New York: Hemisphere Publishing.

Rusbult, C. E. (1980). Commitment and satisfaction in romantic associations: A test of the investment model. Journal of Experimental and Social Psychology, 16, 172-186.

Rusbult, C. E., Zembrodt, I. M., \& Gunn, L. K. (1982). Exit, voice, loyalty, and neglect: Responses to dissatisfaction in romantic involvements. Journal of Personality and Social Psychology, 43, 1230-1242.

SAS Institute Inc. (2000). SAS (Version 8.1). [Computer Software]. Cary, NC: SAS Institute Inc.

Seeman, T. E., Unger, J. B., McAvay, G., \& Mendes de Leon, C. F. (1999). Self-efficacy beliefs and perceived declines in functional ability: MacArthur studies of successful aging. Journals of Gerontology, Psychological Sciences, 54B, P214-P222.

Shewchuk, R. M., Foelker, G. A., \& Niederehe, G. (1990). Measuring locus of control in elderly persons. International Journal of Aging and Human Development, 30, 213-224.

Singer, J. (1998). Using SAS PROC MIXED to fit multilevel models, hierarchical models, and individual growth models. Journal of Educational and Behavioral Statistics, 23, 323-355.

Skinner, E. A. (1992). What are the origins of perceived control? In Perceived control, motivation, and coping: Vol. 8. Individual differences and development series (pp. 45-64). Newbury Park, CA: Sage.

Tallis, F., Eysenck, M., \& Mathews, A. (1992) A questionnaire for the measurement of nonpathological worry. Personality and Individual Differences, 13, 161-168.

Thompson, S. C., \& Spacapan, S. (1991). Perceptions of control in vulnerable populations. Journal of Social Issues, 47, 1-21.

Townsend, A. L., Miller, B., \& Guo, S. (2001). Depressive symptomatology in middle-aged and older married couples: A dyadic analysis. Journal of Gerontology, 56B, S352-S364.

Turvey, C. L., Wallace, R. B., \& Herzog, R. (1999). A revised CES-D measure of depressive symptoms and a DSM-based measure of major depressive episodes in the elderly. International Psychogeriatrics, 11, 139-148. 
Walen, H. R., \& Lachman, M. E. (2000). Social support and strain from partner, family, and friends: Costs and benefits for men and women in adulthood. Journal of Social and Personal Relationships, 17, 5-30.

Ware, J. E., \& Sherbourne, C. D. (1992). The MOS 36-item short-form health Survey (SF-36): Conceptual framework and item selection. Medical Care, 30, 473-483.

Wolinsky, F. D., \& Stump, T. E. (1996). Age and the sense of control among older adults. Journal of Gerontology: Social Sciences, 51B, S217-S220.

Direct reprint requests to:

Elizabeth Hay

P.O. Box 115911

536 McCarty Hall C

Department of Psychology

University of Florida

Gainesville, FL 32611-5911

e-mail: ehay@ufl.edu 